\title{
El primer caso en la Administración Local de una Empresa Mixta Inmobiliaria
}

\section{Un camino nuevo para Diputaciones y Ayuntamientos}

Reconocida por la Base 18 de la Ley de 1945, en concordancia y aplicación con las $17,19,47$ y 54 la facultad de explotar directamente servicios de naturaleza mercantil, industrial, extractjva, forestal o agrícola, se abre con ello un camino de amplisimo porvenir a Diputaciones y Ayuntamientos. El concepto general de industrialización o explotación inicia un giro desconocido y abre un inmenso margen, que viene a ratificar el ya emprendido camino de municipalización de servicios y el modernísimo, que la Ley de Bases recoge, de provincialización. Son nuevas actividades, que dan al traste con el concepto antiguo de considerar extrañas a la Administración estas nuevas facultades.

Con esta base esencial, ¿cuántos servicios de primera necesidad o de utilidad pública pueden acometer Ayuntamientos y Diputaciones? Realmente pueden. ser incontables. Sólo falta arresto y decisión en Corporaciones y funcionarios. Los Ayuntamientos con sus numerosísimos servicios pueden dar ejemplo de ello. Las urbanizaciones, los ensanches, mataderos, mercados, electricidad, alumbrado, recogidas de basuras, administración de su patrimonio y tantos y tantos que la Ley de Bases, y antes la Ley y Estatuto Municipal les atribuían, pueden ser y deben ser orientados en forma de explotaciones mercan- 
tıles. En las obras de ensanche y urbanización -principalmente- en muchos Municipios, se acometen equivocadamente. Llegan por lo general tarde, cuando hay construídas numerosísimas єdificaciones, que hacen enormemente caro sus expropiaciones, o se limitan, con las contribuciones especiales, a implantar unos servicios que desde mucho antes debieron funcionar. Pero aún $\in \mathrm{n}$ los Ayuntamientos que se adelantan y construyen los servicios de alcantarillado, agua, luz, encintado, afirmado, etc., no aprovechan totalmente los medios que la Ley pone en sus manos, y no llegan a explotarlos en su integridad como debiera en beneficio de las propias Corporaciones y vecindario. Las Entidades locales tienen todos los medios necesarios, y son las únicas que mejor pueden explotar con fines mercantiles estas ciases de actividades. Hasta ahora se ha considerado necesario para urbanizar terrenos a los particulares propietarios y al Ayuntamiento. ¿Por qué no se puede pensar en reunir estos dos elementos y ser los Ayuntamientos los explotadores del servicio para una vez urbanizado construir y vender como cualquier particular? Con la nueva Ley creemos que todo será posible.

Esta idea central, por lo que a la Diputación de Asturias se refiere, y en relación a sus bienes patrimoniales, es la que prevaleció, iniciándose con ello el primer caso de Empresa mixta que se ha constituido en España para construcción y explotación de inmuebles. Si la urbanización, venta de sus terrenos y construcciones se considera un positivo negocio, ¿ por qué desligarse de él y dejar este seguro beneficio a otros y con perjuicio del patrimonio de la Corporación? La teoría de considerar extrañas estas actividades a las Entidades locales, más bien parecen patentes de mala administración o intereses de encontrados particulares. Hoy no pueden sostenerse, y hay que administrar hasta sus últimas consecuencias. Este mismo criterio puede $y$ debe aplicarse a las numerosísimas actividades de las Corporaciones.

Por lo que se refiere al desarrollo de urbanizaciones y cons- 
trucciones de inmuebles, son las pocas actividades de particulares, y las numerosísimas Sociedades Inmobiliarias las que se aedican a estas actividades. La necesidad de estas últimas queda demostrada por el gran número de Sociedades constituidas. Hoy el capital privado individualmente no puede llegar a construir todo lo que se necesita. De esta realidad nacen estas nuevas formas. De esta misma necesidad debieran los Ayuntamientos partir para prestar un servicio de utilidad y llegar hasta donde los particulares no pueden, acometiendo estas grandes empresas constructoras que son genuinamente municipales.

Base esencial de ellas será un estudio financiero y estadístico veraz, tanto del crecimiento natural y vegetativo de la pobiación, como de su crecimiento provocado o artificial; del estudio de las verdaderas necesidades de viviendas, clasificadas por las distintas clases sociales; y complementado por la capacidad de absorción económica de cada una de ellas. Con estudios serios y veraces se puede llegar a sentar las bases de esta nueva forma de Empresa, que den la seriedad necesaria, y que, como ninguna, puede responder a la buena marcha de ella, y a la garantía que supone el que Corporaciones públicas intervengan en su desarrollo.

Nuestra Diputación de Asturias, tomando por base todas esas premisas, y teniendo en lo mejor de Oviedo unos magnificos solares que fuerón destinados a antiguo hospital, aplicó estas nuevas tendencias en Diputaciones, y pidió autorización ai Ministerio de la Gobernación para que adelantándose a la pubiicación de la Ley articulada de Administración. Local, nos declararan aplicables las bases ya existentes, y pudiera, la Diputación, constituir una Empresa mixta para la construcción y explotación de inmuebles en los terrenos del antiguo hospital. Abonaba esta petición, la ya intensa actividad de nuestro Organismo provincial, modelo en estas lides mercantiles e industriales, al tener, entre otros servicios industrializados, la explota- 
ción en régimen directo del servicio de alquiler de más de sesenta camiones y autobuses. Su mayoría de edad quedó sancionada al crear y sostener este servicio en igualdad económica, financiera y tributaria con el resto de los particulares.

Hechos los estudios pertinentes y consultados destacados elementos financieros, y con el asesoramiento y la base de nuestra Caja de Ahorros de Asturias, se llegó a concertar la posibilidad de la creación de una potente Empresa mixta, con las aportaciones de las Cajàs de Ahorro Benéficas de España.

Con estos estudios y posibilidades y con la historia. de seriedad y trabajo de nuestra Diputación, se solicitó la correspondiente autorización, que dada la envergadura de la Empresa, fué sancionada en Consejo de Ministros por Decreto de fecha 8 de febrero de 1947 ("Boletín Oficial del Estado" del día 27 de marzo), por la que.se nos autorizó a constituir una Empresa mixta para la construcción y explotación de viviendas, aportando los terrenos del antiguo hospital, y percibiendo su importe en acciones, quedando así exceptuada de la venta en subasta.

Con este importante adelanto de las actividades en la nueva Ley, la Corporación redactó los correspondientes Estatutos de la "Sociedad Anónima Sedes", que una vez aprobados sirvieron de base a la escritura notarial de constitución. Igualmente se aprobó la tasación hecha por arquitectos de los terrenos, y la Diputación como primera partida aportó la cifra de más de $\mathbf{1 6}$ millones de pesetas a la nueva Sociedad. El resto hasta $100 \mathrm{mi}$ liones de pesetas lo hicieron en metálico por la Caja de Ahorros de Asturias, la Caja de Ahorros y Monte de Piedad de Madrid, Caja General de Ahorros y Monte de Piedad de Zaragoza, Caja de Ahorros y Monte de Piedad Municipal de Bilbao, Caja de Ahorros de la ciudad de Vitoria y Caja de Ahorros Municipal de Burgos.

Nervio y base de su organización son sus Estatutos. En ellos habia que conjugar la garantía y el interés de la Diputación, cun el interés y garantía de los intereses particulares representados por las Cajas de Ahorro. La continuidad de la marcha de la Empresa tenía asimismo que estar asegurada. Todo se estudió y se discutió, y se llegó a un feliz resultado, en donde al 
interés y las garantías que unas partes y otras necesitaban se unió la continuidad con la eficacia. Primeramente para ello, en el gobierno y administración de la Sociedad, la Diputación se reservó seis de los quince Consejeros. La mî́ad de carácter nato recaen en los cargos de Presidente, Secretario e Inierventor de la Diputación y otros tres entre Diputados o Gestores, libremente elegidos por la Asamblea General, y siempre a propuesta del propio Consejo de Administración. La parte de capital privado, con objeto de que la continuidad y la eficacia presida la Sociedad, al igual que la Corporación provincial, tiene ctros dos Consejeros natos en los cargos de Director y Directur-Adjunto de la Caja de Ahorros de Asturias. El resto hasta siete Consejeros más, son todos electivos por la Asamblea general de entre Presidentes, Directores o Consejeros de las Cajas de Ahorro. Con este cuerpo de administradores los intereses de unos y otros están armónicamente compensados, la necesidad cie la continuidad asegurada, y con consecuencias de que no creemos que ninguna Sociedad similar pueda presentar un cuadro de mayor eficacia. Unida ả la garantía y seriedad, que ya dt por sí impone y llevan Instituciones de tanto prestigio como Dipuiación y Cajas de Ahorros.

Al lado de esta básica cuestión, en los Estatutos también se estudió el quorum de los acuerdos esenciales. Así los de fusión con otras Sociedades, aumento de capital, traspaso, venta o liquidación del activo; modificación de los Estatutos; disolución c. cualquier o:ro de capital importancia, además de necesitarse sesión extraordinaria de la Asamblea general, y de estar presente la mayoría del capital social, se necesita el voto de las dos terceras partes del capital presente, con objeto de garantir mutuamente (Diputación y capital privado) la vida y cumplimiento ds los fines sociales. Así un pequeño grupo o pequeña tendencia, nunca puede poner en peligro intereses vitales. Los votos en la Asamblea general son por acciones, y en el Consejo de Administración por Consejeros. En unión de estos órganos rectores funciona un Consejo Permanente compuesto por los Consejeros natos y presididos por el Vicepresidente de la Sociedad.

- El resto de los Estatutos contienen la reglamentación currien- 
tc de esta clase de Sociedades Anónimas, exigidas en el Código de Comercio, con su finalidad, denominación, domicilio, su capital formado por $\mathbf{1 0 0 . 0 0 0}$ acciones de $\mathbf{1 . 0 0 0}$ pesetas que dan derecho al activo social, con el carácter de al portador, cotizables en Bolsa, reparto de dividendos, facultades de la Asamblea y del Consejo, del Director-Gerente, del Consejo Permanente, reuniones, liquidación de ejercicios, beneficios, disolución de Sociedad y disposiciones sobre aportación de capitales, constitución del primer Consejo de Administración y adicionales necesarias.

Es cuestión cle capital importancia para la vida de estas Sociedades Inmobiliarias el gran número de exenciones de tributos que la legislación les ha reconocido. Las Corporaciones locales por el artículo 218 del Decreto de Hacienda de 25 de enero de 1946, quedan exceptuadas de la tarifa 2. ${ }^{a}$ de Utilidades, por todos los beneficios que procedan de cualquier forma de explotación, y los de la tarifa 3. ${ }^{a}$ también se les reconoce la exención para todas las formas de explotación, pero no cuando tengan la de Empresa mixta. Pero al lado de este género de exenciones de las Corporaciones locales, existen otras otorgadas en razón a la finalidad de las Sociedades Inmobiliarias. Estas son más amplias. Están reconocidas por el artículo 38 de la Ley de Reforma Tributaria de 16 de diciembre de 1940, que dispuso en forma general la exención de la $2 .^{a}$ y $3 .^{a}$ tarifa de Utilidades; del impuesto del timbre y sobretimbre de emisión y negociación de acciores de las Empresas que se dedicaran exclusivamente a la adciuisición y construcción de fincas urbanas para su explotación. Igualmente por la Ley de Presupuesto de 31 de diciembre de 1946, se prorrogó por el año de 1947 la exención del pago de derechos reales y timbre, por los actos de constitución de la Empresa, la puesta en circulación de sus acciones y la escritura de su constitución social, siempre que el alquiler de los pisos no pasase de 500 pesetas mensuales. Como se ve, las exenciones de tres impuestos-utilidades, timbre y derechos reales incluye di. 
versas bases o tarifas de gran importancia. Estas exenciones son de dos clases: una que se da a todas, sin limitación de precio de alquiler del piso, pero con cierta restricción en sus actividades al limitar la libre venta de inmuebles; y otra de derechos reales y timbre por los actos constitutivos de la Sociedad, pero reducida a que las rentas de alquiler sea inferior a 500 pesetas mensuales. Unas y otras otorgan, con arreglo a la tramitación, que disposiciones complementarias ha dictado Hacienda.

Al lado de estas exenciones están las concedidas para las construcciones de las llamadas casas para clase media, que no tienen un señalado interés para las Inmobiliarias.

Otro de los requisitos que se tiene que tener en cuenta es si la Empresa pasa o no de cinco millones de capital. En su caso, hay que solicitar la reglamentaria autorización del Ministerio de Hacienda, que se refiere a toda Empresa de cualquier clase que exceda de dicho capital y en virtud de las Leyes de 19 de septiembre y 10 de noviembre de 1942, 15 de mayo de 1945 y 31 de diciembre de 1946 , y reguladas en la Orden de 28 de febrero de 1947. Es una simple fiscalización administrativa sin la cual no puede hacerse la inscripción en el Registro Mercantil, de la nueva Sociedad.

Resueltos todos los problemas y tramitados todos los procedimientos, esta Diputación de Asturias constituyó en los primeros días de mayo la "Sociedad Anónima Sedes", ante el notario don Luis G. Arango, de Oviedo, que nace a la vida jurídica cumo adelantado, de las que puedan en España constituir las Corporaciones locales. Hechos los trámites de las correspondientes inscripciones en el Registro de la Propiedad, por las que aporta la Diputación, a su vez se ha inscrito en el Registro Mercantil, quedando con ello plena de facultades legales la nueva Sociedad.

Lo que parece paradójico es el hecho que sea una Diputación, y no un Ayuntamiento, el que inicie esta específica nueva forma juridica de Empresa. Estos, con sus finalidades, sus grandes medios, sus planes de ensanche y urbanización, los que su- • ponen el importe de las contribuciones especiales, y los nume- 
rosísimos de arbitrios que gravan la construcción, que o bien fudieran servir para rebajar y abaratar la construcción o acumular su importe al precio de la explotación de los inmuebles de. la Empresa mixta, son o hubieran debido ser los más indicados.

Manuel Blanco

Secretario de la Diputación de Asturias. 